\title{
The sexuality of a colostomized person as a major component of quality of life and nursing care
}

\author{
Cristilene Akiko Kimura ${ }^{* 1,2}$, Ivone Kamada ${ }^{1}$, Dirce Bellezi Guilhem ${ }^{1}$, Breno Silva de Abreu ${ }^{1,2,3}$, Renata Costa \\ Fortes $^{2,3}$, Walquiria Lene dos Santos ${ }^{2,4}$ \\ ${ }^{1}$ Sciences and Education Sena Aires College, University of Brasilia, Brasilia, Brazil \\ ${ }^{2}$ Faculdade de Ciências e Educação Sena Aires, Valparaíso de Goiás, Brazil \\ ${ }^{3}$ Universidade Paulista, Brasília, Brazil \\ ${ }^{4}$ Universidade Federal de Goiás, Goiânia, Brazil
}

Received: December 15, 2016

DOI: $10.5430 /$ jnep.v7n8p104
Accepted: February 20, $2017 \quad$ Online Published: March 23, 2017

URL: https://doi.org/10.5430/jnep.v7n8p104

\begin{abstract}
The colostomized person's perceptions regarding sexuality and sexual activity is a major component of quality of life and nursing care, however due to several limitations, the questionnaire only approach, although validated for such applications, has not enough resolution, due to its qualitative approach, to capture more delicate aspects of the impact of an ostomy onto a otherwise healthy patient. In order to correct such bias, a exploratory-descriptive study of a qualitative approach based on Bardain's content analysis was conducted. 80 colostomized participants were recruited from Stomatology Outpatient Clinics in the Hospital de Base, Regional Hospital of Asa Norte and the Regional Hospital of Gama, Distrito Federal, Brazil. Data was collected through a clinical and sociodemographic questionnaire, as well as an individual interview. The results are presented in five categories: self-concept, leakage issues, odor and gases, stigma, sexual activity and companionship. The analysis suggests that the fulfillment of nursing care ideals, through clear and objective communication, results in the colostomized person's care and can favor in the acceptance of their new way of living. The exchange of knowledge and practices between the colostomized patient and the medical care support crew, in special the nursing care, allows the establishment of strategies that contribute gradually to the full health care, promoting the improvement of the QoL of both the colostomized person as well his/her partner. It is concluded that health services should provide care process in health and nursing, with the purpose of guaranteeing means for the planning of a holistic implementation of health care. This planning should include the psychological support and the educational process that develops one's ability for self-care, which may interfere in the role of sexuality and sexual activity, in addition to the physiological, psychological and social issues.
\end{abstract}

Key Words: Ostomy, Quality of life, Sexuality, Nursing care, Full health assistance

\section{INTRODUCTION}

For an intestinal ostomized person, the meaning of the physical changes in body as well as the suffering caused by the new lifestyle due to the use of collector equipment strongly impacts social performance and personal relationships. With an altered body image and low self-esteem, the ostomized adopt a posture of detachment and social isolation, ${ }^{[1-6]}$ because they become concerned about gases, eliminated faeces' odor, leakages and physical discomfort. This set of factors influence the sexuality and sexual activity of the in-

\footnotetext{
*Correspondence: Cristilene Akiko Kimura; Email: cris.akiko7@gmail.com; Address: SQNW Quadra 311 Edifício Montparnasse Bloco B Apto 116 Setor Noroeste - Distrito Federal, Brasil.
} 
testinal ostomized people, compromising their quality of life $(\mathrm{QoL})^{[2,7]}$

The World Health Organization defines QoL as "the individual's perception of his position in life in the context of the culture and value system in which he lives and in relation to his goals, expectations, standards and concerns". ${ }^{[8]}$ In this perspective, QoL is a subjective and complex concept that involves personal satisfaction in several aspects, especially those considered essential to one's life. Maintaining physical integrity is very important for the person to feel good about him/herself and at his/her social environment. The rupture of this integrity, caused by the confection of an intestinal stoma that results in the use of a colostomy bag, can bring serious issues of physical, psychological and social order. ${ }^{[3]}$

Hence, health professionals should provide full health care to the ostomized person including in the caring approach, the development of competences and skills to deal, for instance, with the sexuality issue. ${ }^{[2,6]}$ One of the aims of the caring process for the person with intestinal stoma is rehabilitation, another one is the aid in identifying and overcoming barriers regarding sexuality and resumption of such sexual activities. $^{[1,7]}$

Sexuality topic should be part of the full health care approach by health professionals, including the preparation of the patient in their preoperative period to the confection of the intestinal stoma, since it is a aspect that plays a major role for the colostomized person regarding the resumption of the sexual activities and maintaining the integrity of the psychosocial being and reaching an improvement of QoL.

Based on these considerations, the present study aimed to analyze the colostomized persons' perceptions regarding sexuality and sexual activity as a major component in quality of life and nursing care, assisted by the Ambulatory Assistance to the ostomized Program of the Health Department of Federal District, Brazil.

\section{TOOLS AND METHODS}

\subsection{Study design}

This is an epidemiological-based, exploratory-descriptive study with a qualitative approach based on Bardin's content analysis. The research protocol was approved by the Research Ethics Committee of the Health Sciences and Research Foundation of the State Health Secretariat of the Federal District, Brazil, under protocol number 418/200. The individuals who agreed to participate in the study signed the Inform Consent, after receiving detailed explanation about proposed goals, risks and procedures. Privay regarding the data and the anonymity of the volunteers have been guaranteed, according to Brazilian regulations. ${ }^{[9]}$ In order to maintain the anonymity and preservation of the identity of the research participants, the letter $\mathrm{P}$ followed by Arabic numerals from 1 to 18 was used in sampling.

\subsection{Recruitment}

The recruitment process initiated on February 2, 2015, being performed until February 12, 2015. The study fulfilled the schedule, being completed according to the original planning, without interruptions of any sort.

\subsection{Casuistry}

The inclusion of the participants in the study was done by means of intentional non-probabilistic sampling based on spontaneous willingness to participate in the study. The study also counted on the collaboration of 80 colostomized people recruited from the Ostomy Outpatient Clinics of the Hospital de Base, the Regional Hospital of Asa Norte and of the Regional Hospital of Gama, registered in the Ambulatory Care to the Ostomized Program of the Secretariat of Health of the Federal District, Brazil.

\subsection{Eligibility criteria}

The inclusion criteria for the selected patients was the following: men and women older than 18 years of age, colostomized, with definitive intestinal stoma and stable marital status, who demonstrate understanding and conditions to continue the data collection in outpatient clinics and to agree to participate in the research, by signing the Informed Consent Forms. Exclusion criteria were: children, adolescents, pregnant women, infants, bedridden and other physically disabled patients.

\subsection{Data collection}

The sociodemographic and clinical questionnaire applied contained the following variables: sex, age, religion, religious practice, level of formal education and familiar income. Regarding the clinical data, the following variables were observed: time of being colostomized, cause of the stoma, presence of irrigation system as well as comorbidities. Interviews were performed in a private room in order guarantee the privacy of participants. The interview was initiated by obtaining identification and characterization of the participant, as well as the health services that they were part of and their outpatient follow-up, objectively asking how has the colostomy impacted the patients sexual aspects of life.

The interview was done individually through directed questions. This type of interview is based on the use of a script as information collecting tool, which ensures that the same question will be asked in the same way to all people being interviewed. In addition, the interview is developed from a 
fixed list of questions, in which the order and writing remain invariable for all respondents. ${ }^{[9]}$

The interviews were recorded presenting an average length of 60 minutes, which were processed immediately after the sessions, in order to optimize the interviewers memory and perception regarding those patients session. The successive readings of the material served to the analysis and elaboration of the categories of the study. Also, the annotations in the field journal were analyzed as complementation of the reports, especially in the register of the attitudes of the interviewees.

Such approach based on the recording, analysis and definition of main qualitative categories is considered a methodology named Bardin's Content Analysis, ${ }^{[11]}$ which is based on scheme to describe and prepare the material, followed by inference or deduction and interpretation of the data obtained on the interview. It is based on operations of dismemberment of the text in units as means to reveal the different cores of meaning that forms the communication, and later, to make its regrouping in classes or categories, being one of the most appropriate ways to the qualitative studies. In that way, it is possible to attain more information that would be, otherwise, ignored by simple qualitative questionnaire evaluation.
The process of Bardin's Content Analysis is a sequential process presenting phases such as: The pre-analysis of the data, by first readings of contact with the texts, followed by choice of the documents to be considered (in this case, the transcribed reports), the formulation of the hypotheses and objectives (related to the research), the indexing of indices, the elaboration of indicators (the frequency of appearance of a determined unit of text) and the preparation of the material.

In the next phase, exploration of the material which is the most enduring and laborious period which entails the codification stage (recognizing the reccuring aspects of interview and determining the importance of such as means to assess the impact of colostomy in sexuality) and the categorization phase, in which the requirements for a good category are mutual exclusion, homogeneity, pertinence, objectivity, fidelity and productivity.

In data analysis phase, a procedure guided us in the inclusion of the information obtained and that served this study's purpose. In this way, we think of creating a grand thematic axis and, from it, categories that allowed us to explore the wealth of information obtained through colostomized people. The schematic diagram (see Figure 1) illustrates the division described above.

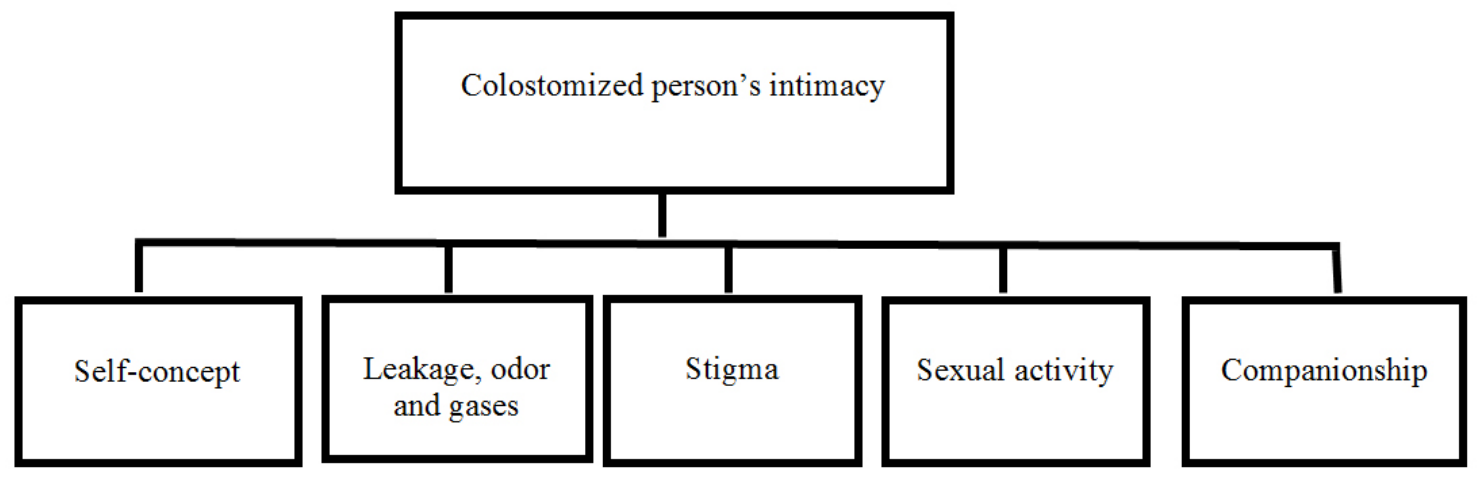

Figure 1. Schematic Diagram (Brasília, DF, Brazil, 2016)

\subsection{Statistical analysis}

The descriptive statistical analysis of the data was performed using averages and standard deviation, using Microsoft $\mathrm{R}$ Office Excel version 2016 and SPSS (Statistical Package of the Social Sciences, SPSS Inc., Chicago, USA) for Windows version 24.0. Statistical significance accepted was 5\%.

\section{Results}

The sociodemographic characterization of the participants showed that, amongst 80 participants of this study, the average age was $56.64 \pm 13.67$ years old, and the majority of the volunteers presented age between 51 and 60 years old $(47.5 \%)(n=38)$. The second most frequent range was $61-70$ years old $(18.8 \%)(\mathrm{n}=15)$. There was a higher prevalence in females, represented by $61.2 \%(n=49)$.

Regarding religious aspects, most individuals reported being catholic, with $58.8 \%(\mathrm{n}=47)$ and protestants $(36.2 \%)(\mathrm{n}=$ 29 ). Concerning the definition of religious practice, $85 \%$ (n $=68$ ) declared that are active members of the community. The determination of the education level showed a predominance of elementary school, with $67.5 \%(\mathrm{n}=54)$. The family income, referred in terms of minimum wage values in 2015 ( $\mathrm{R} \$ 788.00)$, ranged from less than one and equal to three minimum wages $(68.8 \%)(n=19)$. Table 1 shows all the variables of the sociodemographic questionnaire. 
Regarding the clinical aspect, the variable "time since colostomy" indicated predominance in the range $>12$ months and $\leq 60$ months, corresponding to $63.8 \%(n=51)$ of the participants. Regarding the use of the irrigation system, $3.8 \%$ $(n=3)$ used the system and $96.2 \%(n=77)$ did not use it. About the comorbidities, $47.5 \%(n=38)$ had hypertension and $23.8 \%(n=19)$ Diabetes Mellitus. Among the individuals, active smokers were accounted for $40 \%(n=32)$ of the individuals. All variables of the clinical questionnaire can be seen in Table 2. Regarding the cause for undergoing intestinal stoma, the most common was colorectal cancer $56.2 \%(n=45)$, the demonstration of the causes of stoma confection is described in Figure 2.

Table 1. Sample of colostomized people according to sociodemographic characteristics (Brasília, DF, Brazil, 2016)

\begin{tabular}{|c|c|}
\hline \multirow{2}{*}{ Variables } & Colostomized \\
\hline & $\mathbf{N}$ \\
\hline
\end{tabular}

\begin{tabular}{lll}
\hline Gender & & \\
Female & 49 & 61.2 \\
Male & 31 & 38.8 \\
Total & 80 & 100 \\
Age group & & \\
$20-30$ & 5 & 6.2 \\
$30-40$ & 8 & 10 \\
$40-50$ & 14 & 17.5 \\
$50-60$ & 38 & 47.5 \\
$60-70$ & 15 & 18.8 \\
Total & 80 & 100 \\
Religion & & \\
Catholic & 47 & 58.8 \\
Evangelical & 29 & 36.2 \\
Spiritists & 3 & 3.8 \\
Other & 1 & 1.2 \\
Total & 80 & 100
\end{tabular}

\begin{tabular}{|c|c|c|}
\hline \multicolumn{3}{|l|}{ Religion practice } \\
\hline Yes & 68 & 85 \\
\hline No & 12 & 15 \\
\hline Total & 80 & 100 \\
\hline \multicolumn{3}{|l|}{ Instruction } \\
\hline None to Elementary School & 54 & 67.5 \\
\hline High School & 22 & 27.5 \\
\hline Higher Education & 4 & 5 \\
\hline Total & 80 & 100 \\
\hline \multicolumn{3}{|l|}{ Family income (MW*) } \\
\hline$<1$ a $3 \mathrm{MW}$ & 55 & 68.8 \\
\hline 4 a $5 \mathrm{MW}$ & 24 & 30 \\
\hline$\geq 6 \mathrm{MW}$ & 1 & 1.2 \\
\hline Total & 80 & 100 \\
\hline
\end{tabular}

According to the Bardin's Content Analysis, it was possible Published by Sciedu Press to consolidate the statements in a thematic axis, resulting in five categories: self-concept, leakage, odor and gases, stigma, sexual activity, and companionship presented below.

Regarding the self-concept category, the reports of the colostomized people present evidence the strength of alteration of the body image and the self-esteem influencing the psychological well-being. In this sense, the following interview transcripts are presented:

"My body is different, I feel like you half a woman [...]." (P1)

"I am a body that lacks a piece; I am not equal to other people [...]." (P2)

"I have to live with it and it's difficult." (P3)

"It is very difficult to see myself in the mirror with this body [...]." (P4)

Table 2. Sample of the colostomized people according to the clinical features (Brasília, DF, Brazil, 2016)

\begin{tabular}{|c|c|c|}
\hline \multirow{2}{*}{ Variables } & \multicolumn{2}{|c|}{ Colostomized } \\
\hline & $\mathbf{N}$ & $\%$ \\
\hline \multicolumn{3}{|c|}{ Colostomized condition time (in months) } \\
\hline$>12$ months $\leq 60$ months & 51 & 63.8 \\
\hline$>60$ months & 29 & 36.2 \\
\hline Total & 80 & 100 \\
\hline \multicolumn{3}{|l|}{ Ostomy cause } \\
\hline Colorectal Cancer & 45 & 56.2 \\
\hline Perineal Abdomen Traumas & 12 & 15 \\
\hline Inflammatory Bowel Disease & 10 & 12.5 \\
\hline Chagas Disease & 4 & 5 \\
\hline Diverticular Disease & 7 & 8.8 \\
\hline Fournier's Syndrome & 2 & 2.5 \\
\hline Total & 80 & 100 \\
\hline \multicolumn{3}{|l|}{ Irrigation system usage } \\
\hline Yes & 77 & 96.2 \\
\hline No & 3 & 3.8 \\
\hline Total & 80 & 100 \\
\hline \multicolumn{3}{|l|}{ Comorbidities diabetes mellitus } \\
\hline Yes & 19 & 23.8 \\
\hline No & 61 & 76.2 \\
\hline Total & 80 & 100 \\
\hline \multicolumn{3}{|l|}{ Arterial hypertension } \\
\hline Yes & 38 & 47.5 \\
\hline No & 42 & 52.5 \\
\hline Total & 80 & 100 \\
\hline \multicolumn{3}{|l|}{ Tabagism } \\
\hline Yes & 32 & 40 \\
\hline No & 48 & 60 \\
\hline Total & 80 & 100 \\
\hline
\end{tabular}




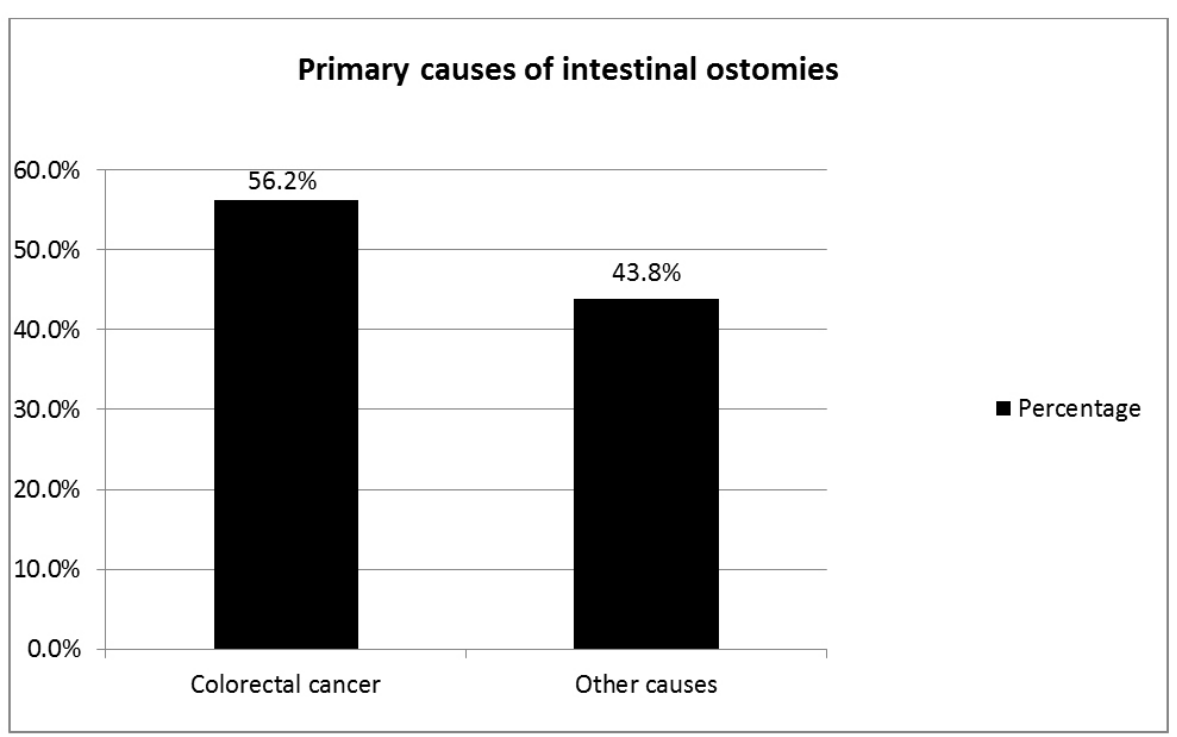

Figure 2. Demonstration of an intestinal stoma primary causes (Brasília, DF, Brazil, 2016)

"For me it is not normal to have a hole in my belly, the most depressing thing is to do my needs in a bag. I have no encouragement at all." (P5)

"Today, when I look at myself, I feel mutilated ... I've always been a person who took care of my body." (P6)

Considering the category of leakage, odor and gases, the reports of the colostomized have shown the meaning of the change in the physical body and the suffering due to the new lifestyle demanded by the ostomy, mainly because the concern about gases, odors from eliminated faeces and leaks, which result in physical discomfort. The descriptions made by the colostomized individuals reinforce this aspect:

"My greatest fear is the leakage of the pouch, the (sic) of releasing gases near someone ..." (P7)

"I can smell odor coming out of the bag. I am very afraid of this being true and the people around me smell it too." (P8)

"I was and I am afraid of being close to someone when the pouch starts to leak, besides, out of sudden those gases and odor come out, so we feel ashamed [...]." (P9)

In stigma category, the speeches of the colostomized show the ostomized person incorporates a social stigma, feeling different before his family and society, hence making his own acceptance and adaptation process more difficult which entails deep changes in social lifestyle. This makes the ostomized person feel different, excluded, and experience a sense of rejection. IN those regards, colostomized patients reported:

"I feel like my belly is tied up .... This is a burden to me." (P10)

"I began to think that I would be rejected by people. Just imagine you using a bag to do your needs."(P11)

"It's the worst feeling a person can feel, the one that people do not want you around." (P12)

"I used to always think I was dirty, no matter how much I took a shower, no matter how clean it was ... I thought it was dirty and I smelled bad." (P13)

In sexual activities' category, the data suggests that the sexuality and the sexual activity of the colostomized are intimately related to the notion of self-concept and the consequent alteration of the corporal image, besides reduction of the self-esteem and the perception of sexual attraction. Thus, when asked about the interference of the intestinal stoma in their intimacy, they expressed themselves according to the following transcripts:

"The sex changed [...] I have a feeling that my husband changed [...]." (P14)

"It's very difficult to have sexual intercourse, I feel inferior, a person who is not attractive [...]." (P15)

"After I put this colostomy bag, I do not feel comfortable with my wife [...]." (P16) 
Although the impact previously shown on the sexual spectrum is significant, the findings in the "companionship" category demonstrate that companionship, in relation to sexual activity, as being a positive category. The reports of the following colostomized corroborate this view:

"Thank God I have a life partner who accepted me and love me and that makes me feel better and safe [...]." (P17)

"I have a very kind wife [...]." (P18)

"Sometimes I feel I'm dry [...]. However, my husband does everything to make me feel good." (P19)

\section{Discussion}

The sociodemographic analysis revealed that the average age was 56-64 years old. Studies show a high prevalence of colorectal cancer in the age group over 50 years old as observed. Such data suggests that more than $90 \%$ of colorectal cancer affects individuals aged over 50 years old. ${ }^{[3,12,13]}$ It is worth mentioning that incidence and mortality rates are increasing as the age group advances. The risk of developing colorectal cancer throughout life is $6 \%$ in countries where the incidence is higher. ${ }^{[5,13]}$

A higher frequency of females were observed among the colostomized patients, which is corrborated with the studies conducted by the National Cancer Institute in Brazil, 2015. Expectations account for the emergence of 16,660 new cases of colorectal cancer in men and 17,620 in women in 2016. Above all, these figures correspond to an estimated risk of 16.84 new cases per 100,000 men and 17.10 per 100,000 women. Estimations of the number of new cases of colorectal cancer in 2016, in the Federal District, Brazil, are 570, of which 270 are in men and 320 in women. ${ }^{[12]}$

A higher prevalence of the catholic religion was observed in 58.8\% ( $n=47)$; in addition, $85 \%(n=68)$ of the participants reported being practitioners of some form of religion. Studies point out the faith is an essential aspect that empowers the patient to move on with its life specially when facing new conditions, such as a colostomy and the adjustments in lifestyle that it demands. Illness can trigger spiritual growth, as it reminds the subject of their fragility and induces life purpose's inquirements. In this perspective, studies suggest that spiritual well-being is added not only to physical and psychological states, but also to cultural formation. ${ }^{[3,5,14,15]}$

Above all, religious involvement can present itself as an element that contributes to the disease's coping process which promotes greater adherence to the treatment, reduction of stress and anxiety, as well as induces a seeking a meaning for the new situation. ${ }^{[1,3,16]}$

Published by Sciedu Press
Regarding education level, 54\% $(n=67.5)$ had only high school degree, as the other categories were detected in low frequencies. Some studies ${ }^{[3,16]}$ describe the existence of a relation between more years of formal education and the quality of life, in a sense that people with higher school graduation tend to have a improved quality of life. In this aspect, the results of the study ${ }^{[14]}$ emphasize that economic and financial issues take a toll onto quality of life of people with ostomy. Even low educational levels may be an element linked to the non-prevention of colorectal cancer, due to the precarious clarification about the factors that trigger this type of cancer and lower general information levels of such population. ${ }^{[13,17]}$

About the analysis of the studied colostomized people, in the aspect of clinical features and cause of the ostomy confection, the results pointed that the most frequent cause was colorectal cancer $(56.2 \%)(n=45)$. In this perspective, studies reveal that the profile of people with intestinal stoma presents a predominance of colorectal cancer. ${ }^{[2,5,18-20]}$ In this perspective, it becomes fundamental to health professionals, especially nurses, to be prepared to the increase of the occurrence of colorectal cancer, hence, the demand for a specialized and goal directed practices in nursing shall increase.

Considering that most of the intestinal stoma's causes were colorectal cancer, $23.8 \%(n=19)$ of the patients were also diabetic, so the analysis is reinforced in the studies by Maurício (2014) that present Diabetes Mellitus type II as a higher risk of colorectal cancer, due to the hyperinsulinemic state that characterizes the early stages of this neoplasm. ${ }^{[21]}$ Moreover, the analysis indicated, among the participants, $40 \%$ of the patients were smokers $(n=32)$. According to some studies, it is revealed that, although the colon is not directly reached by the tobacco composition, the carcinogenic substances transported by the bloodstream have a negative impact regarding the risk of developing colorectal cancer. In addition, the number of cigarette packs/year and the duration of the habit contribute to the development of adenomas, consequently increasing the risk of colorectal cancer. ${ }^{[3,22,23]}$

Although a reduced number of people using irrigation is observed, i.e., $3.8 \%(n=3)$ being colostomized, the use of this mechanism was detected. Therefore, even in face of the lack of representativeness, it is necessary to disseminate the technique of irrigation, as well as knowledge and education, by initiative of health professionals. The use of irrigation presents itself as a technique without side effects, which allows intestinal control and still benefits the social and family relationships, promoting the quality of life of the person with the stoma. In addition, irrigation assists in the frequent decrease of colonic bacterial flora and also leads to reduction 
of gas formation. ${ }^{[3,7,24]}$

In the categories of self-concept, leakage, odor and gases, stigma, sexual activity and companionship, it was observed that sexuality is affected from interference with gender, age, marital status, personal, cultural, economic and geographical aspects, as well as physical and emotional health. In face of the descriptions, sexuality and sexual activity depend above all on the individual himself, his relation with himself and with others. ${ }^{[6,7,14]}$

In this sense, it is possible to understand that ostomized people experience changes of psychological, social, physical and spiritual level, and see their own body image distorted, resulting in low self-esteem. The presence of an opening in the abdomen where faeces are eliminated breaks the pattern of the previous sedimented scheme in childhood, of dominance and voluntary control, privacy and autonomy. ${ }^{[2,11,18,20,25]}$

Thus, the performance of an intestinal ostomy leads to occurrences that transform the daily life of a colostomized people. These changes perceived by colostomized people manifest themselves from the loss of a highly valued organ to the decrease of the self-esteem, as well as the alteration of their body image. It is through body image that the individual maintains an internal balance while interacting with the world, and its modification can influence his work skills and social performance. ${ }^{[5,25]}$ In this way, after undergoing intestinal stoma procedure, the individual faces stigmas for being different from now on. Thus, the use of the colostomy bag increases the potential of social stigma due to its leaks, odors and gases, which affect intimacy relations, social interaction and the resumption of daily activities, with necessary adaptations and re-signification of life. ${ }^{[5,25]}$

Among all, there are some changes related to the complications resulting from the surgical act, specifically the nerve injury. The majority of patients with intestinal stomas do not resume their sexual activity or only partially resume, due to several aspects such as physical problems and difficulties with the collector equipment. Besides that, they may have a decreased sense of hygiene during the intimate relationship, or either a feeling of filth and shame or fear of non-acceptance by their partner. ${ }^{[7,19]}$

It is worth noting that although the sexual activity of the ostomized woman is difficult due to the surgery itself, it can also lead to dysuria, pain during sexual intercourse, urinary incontinence, and reduction or loss of libido. ${ }^{[3,7,26]}$ In addition, it interferes in the emotional aspects, such as concern about the partner's acceptance and satisfaction and generates a diminished sense of hygiene. ${ }^{[7,26]}$

Companionship in relation to sexual activity was considered a positive category, so sexuality can be understood as a fundamental aspect of life and it is present from birth to death, presented with its own characteristics in each period of the life cycle. ${ }^{[27]}$ Sexuality is, therefore, the set of emotions, feelings, fantasies, desires and interpretations that the human being experiences throughout his existence. Sexuality is still an integral part of the human personality, associating personal and affective experiences, sociocultural knowledge, beliefs and values constructed throughout history. In this way, sexual relationship cannot be detached from social, historical, anthropological and psychological themes. ${ }^{[27,28]}$

Sexuality is an intrinsic part of the human being and it is considered a basic human need; It is expressed not only in appearance, but especially in individual subjectivity, and it is exclusive for every human being. The way it manifests itself is very personal and plays an important role in the relations that it triggers in the individual and his/her partner. ${ }^{[28]}$

Therefore, sexuality transcends the physiological need and presents as a relation to the symbolization of desire and attraction. Sex produces fierceful emotions and goes beyond physical definitions that are common ground in all moments of life, presenting complex meanings, multifaceted and that concentrate a great load of subjectivity. ${ }^{[7,26,29]}$ Thus, sexual partnership is an essential part of sexuality that can be a positive or negative element in the narrowing and complicity of the couple's well-being. In this way, any changes that occur in the sexuality of the colostomized person can be considered intense and mutilating, and in this sense, the sexual activity itself admits secondary character, being fully replaceable by a profusion of correlated feelings, reciprocal love, affection, admiration, respect and companionship. ${ }^{[3,7,26,29]}$

The changes that have occurred in people with colostomy have led them to face difficulties in the social sphere, including their sexual life after the intestinal ostomy's confection. Social reintegration is a challenge for these people, who will have to develop coping measures. In view of the above, the intestinal stoma entails visible and significant physical alteration of the body, which can transform it into a body deprived of its integrity, dynamism and autonomy, that causes internal conflicts and imbalances, sometimes transforming relations with the outside world, with regards to the experience of ostomized people's sexuality included, once it modifies body image. ${ }^{[5,16]}$

Thus, full health care for the patient with intestinal stoma poses a challenge for health professionals and especially for nursing. The reason is that it involves changes of all kinds for this patient, such as: bodily changes; in sexuality; in sexual activity; review of habits, values and beliefs; incorporation of professional knowledge; access to services in the public 
health system and need of collector equipment, as well as changes in their daily life, family and work. ${ }^{[1,6,7]}$

Therefore, it is noted the value of full health care provided by specialized professionals, assisting in the processes of adaptation and rehabilitation, that is, in the interfaces with issues related to body image, self-esteem and self-acceptance, in order to be able to support the colostomized people and their partners. This support encompasses the adjustment to the new lifestyle and the search for new coping tactics for a functional and pleasurable sexual life of both the ostomized and his/her partner. ${ }^{[7,26,29]}$

It is worth mentioning that both the colostomized person and his/her partner lack information about their sexuality. However, health professionals, to act in the rehabilitation of the ostomized person, establish a direct relationship with their patient, through the care, and by this, they need to know their main needs so that they can develop quality care. Health professionals' involvement as well as their qualification are very important to the good performance of actions in caring practice.

Assistance to the colostomized person regarding sexuality and sexual activity is an aspect little approached by health professionals, still existing a lot of difficulty to approach and question about this subject, to both the health professionals and ostomized women. Thus, this contributes to the low knowledge and exploration of these representations and meanings in the caring process in health and nursing. Therefore, the health professional, in particular, the nurse, to address the sexuality of the person with intestinal stoma, will have to overcome many difficulties in relation to the prejudices that involve the theme, because it is related to social, cultural and family values and also to their lack of experience, needing adequate preparation for the majority. ${ }^{[7,26,29]}$

It is understood that the search for knowledge is of great relevance to the nurse. This would facilitate the identification of problems in the area of sexuality and, from there, they would better guide these people, clarifying them about the importance of exercising their sexuality without prejudice and repression and that it is possible to enjoy it at any time in life, even in the condition of being a ostomized person. ${ }^{[26]}$

Nurses are advised to offer to patients a care that seeks to clarify the doubts inherent to the function of the intestinal stoma, how to take care of it and aid in resumption of daily activities. The accomplishment of these nursing cares, through a clear and objective communication, results in quality care to the colostomized person and may favor their acceptance to their new way of life. The exchange of knowledges and practices allow, in a relationship, to establish strategies that contribute gradually to the full health care, promoting the improvement in the QoL of both the colostomized person and his/her partner.

In this perspective, the full health care to the person with colostomy is based on the practices of integrality in health, becoming a challenge for the health professional, especially the nurses, because the approach to this clientele, day to day, requires the consideration of the different ways of being of the colostomized person. Therefore, the acting of health professionals should be based on the holistic evaluation of a human being, in order to offer full, tailored and systematized care, as wells as focusing on the subjectiveness related to the social impact of their new lifestyle.

\section{Limitations}

This study presents limitations related to the ability to capture information that reflects the colostomized person's emotional state in long term. The data here presented is capable of generating a perception about the colostomized person's view on sexuality and sexual activity as an important dimension of the QOL, but it is also given the impossibility of long-term follow-up to cognize the minutiae of the process studied.

\section{Conclusion}

This study allowed reflections about nursing care to the colostomized person, through the analysis of the perception of sexuality and sexual activity as an important dimension in the QoL. The confection of an intestinal stoma causes various disorders to the ostomized person, among them, restriction and change of behavior regarding sexuality and sexual activity.

Thus, research has shown that these changes may be related to changes in body image and self-esteem, stigma, insecurity regarding the collector equipment, the feeling of filth, shame, disgust and fear of not being accepted by the partner. All these changes interfere in sexuality, which leads to QoL impairment.

Furthermore, health services should provide the caring process in health and nursing, in order to guarantee means of planning a full health care that includes psychological support and educational process, in which develop skills for self-care and may play a decisive role in sexuality and sexual activity, in addition to the physiological, psychological and social issues.

\section{Conflicts of InTEREST Disclosure}

The author declares that there is no conflict of interest. 


\section{REFERENCES}

[1] Kimura CA, Guilhem D, Kamada I, et al. Life quality for oostomized patients: a perspective in the health and nursing care process. Journal of Nursing Education and Practice. 2017; 7(4): 22-31. http://dx.doi.org/10.5430/jnep.v7n4p22

[2] Kimura CA, Kamada I, Guilhem D. Quality of life of individual ostomy due oncological reasons: na approach of integrality from Brazilian Unified Health System. Journal of Coloproctology. 2016; 36(1): 34-39. https : //doi .org/10.1016/j.jcol.2015.12.003

[3] Kimura CA, Kamada I, Jesus CAC, et al. Quality of Life of Colorectal Cancer Patients with Intestinal Stomas. Journal of Carcinogenesis \& Mutagenesis. 2014; 5: 1-7.

[4] Salomé GM, Almeida SA, Mendes B, et al. Assessment of subjective well-being and quality of life in patients with intestinal stoma. $\mathrm{J}$ coloproctol. 2015; 35(3): 168-174. https ://doi.org/10.1016/ j.jcol.2015.03.002

[5] Kimura CA, Kamada I, Guilhem D, et al. Quality of life analysis in oostomized colorectal cancer patients. J Coloproctol. 2013; 33(4): 216-221. https://doi.org/10.1016/j.jcol.2013.08.007

[6] Grant M, Ferrell B, Dean G, et al. Revision and Psichometric Testing of the City of Hope Quality of Life Ostomy Questionaire, Quality of Life Research Journal. 2004; 13(8): 1445-1457. PMid:15503840 https://doi.org/10.1023/B:QURE.0000040784.65830.9f

[7] Kimura CA, Kamada I, Guilhem D, et al. Perception of sexual activities and the care process in oostomized women. J Coloproctol. 2013; 33(3): 145-150. https://doi.org/10.1016/j.jcol.201 3.05 .004

[8] The WHOQOL Group. The World Health Organization. Quality of life assessment (WHOQOL): position paper from the World Health Organization. Social Science and Medicine. 1995; 41(10): 1403-9. https ://doi.org/10.1016/0277-9536(95)00112-K

[9] Brazil. Ministry of Heatlh. Nationald Health Council. Resolution N.466/2012. Guidelines and reguling norms for research involving human subjects. Brasilia: CNS; 2012. Availabale from: http: //co nselho.saude.gov.br/resolucoes/1996/Res196_en.pdf

[10] Gil AC. Como elaborar projetos de pesquisa. 4 ed. São Paulo: Atlas, 2007.

[11] Bardin L. Análise de conteúdo. Lisboa: Edições. 2008.

[12] Ministério da Saúde (BR). Secretaria de Atenção à Saúde. Instituto Nacional de Câncer. Estimativas 2015: incidência de câncer no Brasil. Rio de Janeiro: INCA; 2015.

[13] Siegel R, Desantis C, Jemal A. Colorectal cancer statistics. Cancer J Clin. 2014; 64(2): 104-17. PMid:24639052 https : //doi .org/10 .3322/caac. 21220

[14] Dabirian A, Yaghmaei F, Rassouli M, et al. Quality of life in ostomy patients: a qualitative study. Patient Prefer Adherence. 2011; 5(1) $1-5$.
[15] Ramirez M, McMullen C, Grant M, et al. Figuring Out Sex in a Reconfigured Body: Experiences of Female Colorectal Cancer Survivors with Ostomies. 2009; 49(8): 608-24.

[16] Fortes RC, Monteiro TMTC, Kimura CA. Quality of life from oncological patients with definitive and temporary colostomy. J Coloproctol. 2012; 32(3): 253-259. https ://doi .org/10.1590/s2237-9 3632012000300008

[17] Hawkins D, Booth A. Unhappily ever after: affects of long-term, low quality marriages on well-being. Social Forces. 2005; 84(1): 451-475. https://doi .org/10.1353/sof . 2005.0103

[18] Torres CRD, Andrade EMLR, Ribeiro FMSS, et al. Quality of life of ostomized people: an integrative review. Rev Enferm UFPI. 2015; 4(1): $117-22$.

[19] Mahjoubi B, Mirzaei R, Azizi R, et al. A cross-sectional survey of quality of life in colostomates: a report from Iran. Health Qual Life Outcomes. 2012; 10(1): 1-6. PMid:23170951 https : //doi.org/10.1186/1477-7525-10-136

[20] Bonill-de-Las-Nieves C, Celdrán-Mañas M, Hueso-Montoro C, et al. Convivendo com estomas digestivos: estratégias de enfrentamento da nova realidade física. Rev. Latino-Am. Enfermagem. 2014; 22(3): 394-400. https://doi .org/10.1590/0104-1169.3208.2429

[21] Maurício JML. Diabetes Mellitus tipo 2e Carcinoma Colorretal. Faculdade de Medicina da Universidade de Coimbra, 2014.

[22] Repić G, Ivanović S. Physical dimension of quality of life in ostomy patients. Acta Medica Medianae. 2014. PMid:25868306

[23] Stürmer T, Glynn RJ, Lee IM, et al. 'Lifetime cigarette smoking and colorectal cancer incidence in the Physicians' Health Study I'. J. Natl. Cancer Inst. 2000; 92(14): 1178-1181. PMid:10904092 https://doi.org/10.1093/jnci/92.14.1178

[24] Maruyama SAT, Barbosa CS, Bellato R, Pereira WR, Navarro JP. Auto-irrigação - estratégia facilitadora para a reinserção social de pessoas com colostomia. Rev. Eletr. 2009; 11(3): 665-73.

[25] Barbutti RCS, Silva MCP, Abreu MAL. Ostomia, uma difícil adaptação. Revista da Sociedade Brasileira Psicologia Hospitalar. 2008; 11(2): 27-39.

[26] Silva AL, Faustino AM, Oliveira PG. A sexualidade do paciente com estomia intestinal: revisão de literatura. Rev enferm, UFPE on line. 2013; 7(1): 879-887.

[27] Freud S. Três ensaios sobre a teoria da sexualidade. Rio de Janeiro:Edição Standard Brasileira das Obras Completas de Segmund Freud. Imago, 2002.

[28] Amorim VCO, Flores ALGCT, Sexualidade na gestação: mitos e tabus. Revista Pesquisa Psicológica. 2007; 1(1): 16-44.

[29] Paula MAB, Takahashi RF, Paula PR. Os significados da sexualidade para a pessoa com estoma intestinal definitivo. Journal of Coloproctology. 2009; 29(1): 077-082. https ://doi .org/10.1590/s010 1-98802009000100011 